\title{
Construction and Validation of an Occupational Psychological Empowerment Tool for Relief Workers of the Iranian Red Crescent Society

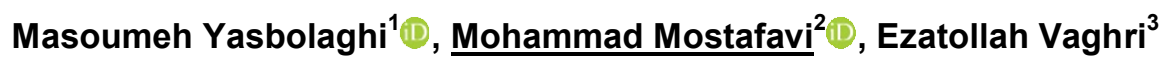

Date of submission: 21 Mar. 2019, Date of acceptance: 24 Jun. 2019

\section{Original Article}

Abstract

INTRODUCTION: Maintaining the mental health of relief workers requires improving their psychological abilities. The present study is carried out with the aim to identify the components affecting the psychological empowerment of the relief workers and to construct a tool appropriate to the psychological requirements and characteristics of the relief activities to measure the components of the occupational psychological empowerment among them.

METHODS: This was an applied study performed with quantitative and qualitative methods (Mixed Method) in different stages in accordance with the study objective.

FINDINGS: In this study, 351 relief workers cooperated with an average age of 28.56 and standard deviation 8.13. The findings from the completion of questionnaires confirmed the six factors of resilience, self-management, psychological hardiness, problem-solving ability, decision-making, and emotional intelligence (EI) on the researcher-made scale. The most important factor in this study was the resilience factor with the greatest impact on the job psychological empowerment of the relief workers.

CONCLUSION: Based on the results of the study, in order to reduce the pressures and stresses of relief in disasters on the relief workers and prevent them from becoming more severe psychological problems, special counseling and psychological support services should be provided to increase their resilience. In addition, the tool developed can be applied to measure the occupational psychological empowerment in volunteers, relief workers, and rescuers. Moreover, based on the scores obtained by the subjects in the scale, it can be considered as a criterion to accept or reject individuals in entering the relief activities. Furthermore, for the individuals accepted according to the characteristics of relief activities, planning can be made and training courses and workshops can be held to teach, empower, and strengthen them and enhance the components of psychological empowerment among them.

Keywords: Construction; Validation; Occupational Psychological Empowerment; Relief Workers

How to cite this article: Yasbolaghi M, Mostafavi M, Vaghri E. Construction and Validation of an Occupational Psychological Empowerment Tool for Relief Workers of the Iranian Red Crescent Society. Sci J Rescue Relief 2019; 11(3): 145-53.

\section{Introduction}

$\mathrm{P}$ sychological empowerment is a set of experienced cognitions that is manifested as a sense of meaning, competence, impact, and self-determination (1-4), and is a kind of increase in intrinsic job motivation that reflects an active personal orientation to work roles and responsibilities (3). In this definition, the meaning dimension indicates the value of the occupational goals or objectives is judged in relation to the individual's personal criteria and ideals (4). Competence means an individual's belief in his or her ability to perform his or her duties skillfully (5). Self-determination is the individual's feeling of having the autonomy to initiate and regulate his or

1-MA, Guidance and Counseling, School of Educational Sciences and Psychology, South Tehran Branch, Islamic Azad University, AND Research Center for Emergency and Disaster Resilience, Red Crescent Society of the Islamic Republic of Iran, Tehran, Iran

2-PhD, Occupational Counseling, Instructor, Khazar Private University, Amol, Iran

3-MA, General Psychology, Kharazmi University AND Research Center for Emergency and Disaster Resilience, Red Crescent Society of the Islamic Republic of Iran, Tehran, Iran

Correspondence to: Mohammad Mostafavi, Email: mostafavi90@gmail.com 
her work activities (6), and finally, impact indicates the extent to which an individual influences strategies, policies, and procedures that is associated with the implementation or application of results at work (7).

The dimensions of competence, selfdetermination (right to choice), meaning, and impact reflect a personal orientation to the role of work in the organization $(3,8)$. Watten and Cameron (1998), while emphasizing the multifaceted nature of empowerment and confirming the above four dimensions, added the dimension of trust to them as well (9).

Psychological empowerment of human resources, as a new approach to job motivation, means releasing the internal strengths of employees and providing the conditions and opportunities to thrive on the talents, abilities, and competencies of individuals. Psychological empowerment begins with a change in the employees' beliefs, thoughts, and attitudes. This means that they must believe that they have the ability and competence to perform tasks successfully and feel that they have the ability to influence and control the occupational outcomes. Besides, they should feel that they pursue meaningful and valuable occupational goals and believe that they are treated honestly and fairly (10).

Due to the wide range of accidents and problems, the Red Crescent Society will not be able to perform its duties properly without the use of volunteer forces. Since the relief workers are at the scene of the accident while helping others, they tolerate a high amount of pressure. The effects of the accident on the relief workers (ambulance staff, nurses, and other relief workers) are so great that Kliman (1976) and Worte (1986) called the relief workers the hidden victims of accidents, which actually stems from the physical and psychological consequences of their operations at the accident scene.

In reviewing 10 major studies on relief workers, Patton (1989) considers common symptoms among them including dreams, nightmares, depression, guilt, feelings of helplessness, anger, anxiety, feelings of deprivation, frequent recollection of events, changes in social, occupational, and family activities, numbness, and other symptoms that can be summarized as post-traumatic stress disorder (PTSD) $(11,12)$.

Given the above issues, and considering that efficient and capable human resources are the most important factor influencing productivity in the Red
Crescent Society, planning to empower them, particularly the relief workers, is of paramount importance, but unfortunately, they are often ignored and are marginalized at the scene of care. In addition, despite much debate about the concept and advantages of empowerment in management literature, little research and practical effort has been made to measure empowerment and develop theory and related factors due to the lack of a single and precise definition on the concept of empowerment $(3,4)$. The understanding of this concept is limited and often confusing (2) and little experimental investigations have been conducted in this field (13) with insignificant use. It seems that the concept of psychological empowerment in the relief workers' community, which is facing risks and crises such as earthquakes, floods, etc., and with its resulting wide dimensions and psychological pressures in providing relief, differs from the concept of psychological empowerment in other societies.

Despite the studies in the area of psychological empowerment, there is no measurement criterion for psychological empowerment of relief workers. Such a criterion can provide therapists and managers with information about the shortcomings of the psychological empowerment of the relief workers and help them understand the lack of aspects of the process of psychological empowerment of the relief workers. Additionally, such a criterion allows experts and researchers to focus on different dimensions of the psychological empowerment of the relief workers. Therefore, this study is performed with the objective to identify the concept of psychological empowerment in relief workers and its dimensions and to design and psychometrically analyze a valid tool to measure their empowerment.

\section{Methods}

This was a type of applied study conducted in several stages using different quantitative and qualitative methods in proportion to the study objective. The samples were selected from 4245 relief workers and rescuers from the Red Crescent Society of Tehran Province, Iran, with a history of participating in rescue operations, among whom 351 subjects were selected using Morgan's table.

In order for the samples to represent the entire community of relief workers of the Red Crescent Society of Tehran Province in 2018 and according to the relief workers population of the Red Crescent Society branches in Tehran Province (13 
branches), weighting was performed and 7 clusters of Pakdasht, Tehran, Shahr-e-Rey, Shemiranat, Robat Karim, Damavand, and Varamin were selected. Then, among the relief workers and rescuers of these 7 clusters, the samples were randomly selected as described in table (1). Taking into account the possibility of a drop in the number of subjects in the research works, $10 \%$ more than the required number of samples was considered and the questionnaire was distributed among the subjects selected. As a result, a total of 381 questionnaires were distributed, of which 351 were returned (Response rate $=92.12$ ).

Table 1. Population and number of samples

\begin{tabular}{|c|c|c|}
\hline & \multicolumn{2}{|c|}{$\begin{array}{c}\text { Red Crescent Society of Tehran } \\
\text { Province }\end{array}$} \\
\hline & $\begin{array}{l}\text { Relief Workers } \\
\text { Population }\end{array}$ & $\begin{array}{l}\text { Sample } \\
\text { Number }\end{array}$ \\
\hline Pakdasht & 430 & 46 \\
\hline Pardis & 5 & - \\
\hline Pishva & 65 & - \\
\hline Tehran & 1870 & 198 \\
\hline Shahriar & 180 & - \\
\hline Shahr-e-Rey & 270 & 29 \\
\hline Shemiranat & 325 & 34 \\
\hline Robat Karim & 210 & 22 \\
\hline Damavand & 230 & 24 \\
\hline Firuzkuh & 135 & - \\
\hline Mallard & 90 & - \\
\hline Eslamshahr & 170 & - \\
\hline Varamin & 65 & 28 \\
\hline
\end{tabular}

The data collection was a researcher-made questionnaire designed in two sections: demographic information and indicators of job psychological empowerment of relief workers in 10 components of resilience, psychological hardiness, creativity, self-efficacy, participation, decision-making, problem solving ability, philanthropy, responsibility, and emotional intelligence. The steps of constructing and determining the validity and reliability of the questionnaire were as follows: In the first stage, by analyzing the content of the relevant texts, the components of psychological empowerment were extracted for the relief workers. Then, 160 items were compiled for these components and to assess the content and face validity of the questionnaire, the items were examined qualitatively and quantitatively by 10 experts in this field and based on the qualitative study, some verbal, conceptual, content, and writing changes were applied in the questionnaire. To examine the instrument quantitatively, the content validity ratio (CVR) was used, for which the total score of 0.81 was calculated. Finally, given the results obtained and consultation with the supervisor, some items were removed and modified and the final version was obtained with 116 items to measure the 10 components of resilience, psychological hardiness, creativity, self-efficacy, participation, decision-making, problem-solving ability, philanthropy, responsibility, and emotional intelligence (EI). The questionnaire was randomly implemented on 30 selected relief workers in a targeted manner and its internal consistency was calculated using the Cronbach's alpha coefficient. In order to investigate the construct validity of the occupational psychological empowerment questionnaire, each item was calculated with the total score and with its psychometric characteristic. The Cronbach's alpha was employed to determine the reliability of the instrument in the initial implementation and the total reliability of the questionnaire was obtained as 0.955 . Moreover, the reliability of the components was calculated separately in the initial stage of the implementation, as 0.912 for the components of resilience, psychological hardiness, and creativity, 0.956 for self-efficacy, 0.953 for participation, 0.935 for decision-making and problem-solving ability, 0.956 for philanthropy, 0.957 for responsibility, and 0.951 for EI. Finally, the correlation of each subscale with the total score was calculated. Finally, 98 items were confirmed with a Cronbach's alpha coefficient of 0.955 .

To measure the adequacy of the sample size and the significance of the information, the Bartlett test and the Kaiser-Meyer-Olkin (KMO) test were employed for the matrix of the exploratory factor analysis (EFA). After analyzing the items with the EFA method, the items higher than one were identified and the number of items was reduced to 98 . After implementing the tool on 381 relief workers of the Red Crescent Society of Tehran Province, using the cluster sampling method and analysis of the data from 351 questionnaires returned, the number of items was reduced to 77 through EFA.

The items were scored on a 5-point Likert scale with 1-5 indicating the options of too little, a little, somewhat, much, and too much, respectively. The score of each subject was obtained summing up the scores of each dimension. The higher the score of the dimensions, the greater the effect of that factor on 
the psychological empowerment of the relief workers. Some items $(27,30,32,38,41,43,50$, $53,58,65,73)$ were numbered inversely. The data obtained in the present study were analyzed in the two levels of descriptive and inferential results in the SPSS software (version 20, IBM Corporation, Armonk, NY, USA), with the descriptive data presented as frequency in the following table.

The Cronbach's alpha coefficient was applied to determine the reliability coefficient and to analyze the data using the EFA method, as the Cronbach's alpha coefficient of the scale was obtained as 0.95 , indicating the acceptable internal consistency of the scale.

\section{Findings}

351 relief workers with a mean \pm standard deviation (SD) of age of $28.56 \pm 8.13$ participated in this study. The demographic findings of the study are as presented in Tables 2 and 3.

Table 2. Distribution of frequency and percentage of subjects by age, marital status, and education level

\begin{tabular}{|l|c|c|c|}
\hline Variable & Index & Number & $\mathbf{\%}$ \\
\hline Age & Female & 143 & 40.7 \\
& Male & 208 & 59.3 \\
Marital & Single & 228 & 65 \\
status & Married & 123 & 35 \\
& Diploma and below & 91 & 26 \\
Education & Associate degree & 40 & 11.4 \\
level & Bachelor's degree & 170 & 48.4 \\
& Master and Ph.D. & 50 & 14.2 \\
\hline
\end{tabular}

EFA was utilized in order to explore the main dimensions or constructs of the study data to design and conceptualize the psychological empowerment of relief workers and to design and build a valid and stable scale to measure their occupational psychological empowerment. The steps and results are as follows.

Table 3. Frequency distribution and percentage of subjects by activity background

\begin{tabular}{|c|c|c|}
\hline Index & Mean & SD \\
\hline $\begin{array}{l}\text { Activity background } \\
\text { Total }\end{array}$ & $\begin{array}{l}7.54 \\
351\end{array}$ & $\begin{array}{l}7.09 \\
100\end{array}$ \\
\hline
\end{tabular}

To measure the adequacy of the sample size and the significance of the information, the Bartlett test and the KMO test were employed for the EFA matrix. In the analysis of the primary factor, considering that the average sampling size adequacy is about $90 \%$, and since it was above $50 \%$ here $(0.900$ which is about $90 \%)$, the questionnaire had the capability to be factorized to an acceptable level (the closer to one, the better). Furthermore, in accordance with the Bartlett's test of Sphericity, since its value $(\mathrm{P}<0.001)$ in Table 4 is less than $5 \%$, so the null hypothesis, i.e. the identity correlation matrix, is rejected, indicating the appropriateness of EFA for the study data. The results of the above two tests were very suitable for EFA of the study data. Therefore, the capability of factorization is confirmed up to here.

Table 4. Results of Kaiser-Meyer-Olkin (KMO) and Bartlett tests

\begin{tabular}{|c|c|c|}
\hline \multicolumn{2}{|c|}{$\begin{array}{l}\text { Kaiser-Meyer-Olkin Measure of } \\
\text { Sampling Adequacy }\end{array}$} & 0.900 \\
\hline $\begin{array}{l}\text { Bartlett's of } \\
\text { Sphericity }\end{array}$ & $\begin{array}{c}\text { Approx. Chi-square } \\
\text { df } \\
\text { P }\end{array}$ & $\begin{array}{c}14674.084 \\
2926 \\
<0.001\end{array}$ \\
\hline
\end{tabular}

After performing the above two tests, EFA was carried out to investigate and identify the main factors and to discover the specific features and relationships among them. These factors had to satisfactorily explain the correlations (covariance) observed among the observed variables. For this purpose, the statistic of the Eigen value of the matrix was used; the factors with a higher Eigen value are the best factors. An Eigen value less than one indicates that the factor only meets a small amount of the total variance, that is, less than what is estimated by a variable (questionnaire item).

The EFA results showed that out of the 77 items measured in the questionnaire, the eight values of 19 factors were more than one, and the percentage of common variance among the variables for these 19 factors together accounted for $67.595 \%$ of the total variance of the variables. In other words, the accuracy of these 19 factors was more than $50 \%$ in total. The proportion of the first factor justified about $29 \%$ of the total variance of variables.

The portion of the factors from the total variance was determined by plotting the scree plot (the proportion of the first factor in the total variance of the variables was more significant and completely distinct from the proportion of the other factors). 
Table 5. Empowerment scale rotation matrix (First factor)

As a member or volunteer of the Society, I am aware of my duties.

In rescue operations, I try more than the assigned tasks.

0.458

To increase my efficiency and effectiveness in the rescue missions, I update my knowledge and information.

I am very successful in my area of expertise (as a relief worker).

0.580

I feel useful in the Red Crescent Society.

If I want to do something, no one or nothing can stop me.

I can offer new ideas in the field of rescue missions.

I do my tasks accurately.

I can do my tasks in the unforeseen circumstances and I can make quick and correct decisions.

0.552

0.553

0.608

I enjoy solving difficult problems.

I use new methods to perform my tasks.

My colleagues and friends consider me a creative person.

0.499

0.592

0.525

0.581

During the rescue operation, I come up with new ideas and effective strategies to promote activities and be more successful.

I have the ability to use the minimum features to solve the problems.

In critical situations, I make the right decision at the right time.

I try to consider all aspects in decision-making.

I am fully aware of the decision-making process.

When I look back, most of the decisions I have made during the rescue operation were correct.

I try to consult with experts before making a decision.

After making a decision, the outcome I usually expect is the same as the real outcome.

0.404

0.607

When necessary, I have no problem making difficult decisions.

When facing with a difficult situation, I would like to gather as much information about it as possible.

When faced with difficult situations, I try to think of possible solutions.

0.678

I can hardly decide on the best solution.

When I have a problem, I try to analyze the facts related to the issue.

If a solution to a problem is failed, I will not try it again.

When my first attempts to solve a problem fail, I doubt my ability to control the situation and worry about.

After trying to solve a problem in a certain way, I compare the real consequences with the expected ones.

I usually face a lot of problems in rescue operations that are very difficult for me to solve.

When faced with a problem, I think carefully and patiently about it before doing anything.

I am sure that if I try hard enough, I can solve all the problems I face.

Accepting the unfortunate realities of life is one of the conditions for the continuation of life.

I can tolerate critical and special circumstances in carrying out relief missions.

In rescue missions, I usually welcome hard tasks.

No matter how hard I try in the Red Crescent Society, my efforts are fruitless.

My efforts in rescue operations are effective in the consequences of the operation team.

After taking part in difficult operations, I could hardly fall asleep at night due to mental conflicts.

Even when the critical conditions are very frustrating, I still do not get disappointed.

I believe that it is expedient in any event, good or bad.

Coping with the stress of the rescue operation scene makes me stronger.

The successes I have had in the past have given me so much confidence that I can deal with the challenges and problems ahead.

Whenever I have a problem, there is no one to count on his/her help.

0.592

0.567

Even when I am under pressure to take part in relief operations, I do not lose focus and

think properly.

When I fail, I quickly become discouraged.

I usually look at the positive aspects of events.

Only by looking at others can I understand their emotions and feelings. 
Table 5. Empowerment scale rotation matrix (First factor) (continue)

Item

I know my emotions well.

It is difficult for me to understand the non-verbal messages of the injured people.

I have complete control over my emotions and feelings.

I am fully aware of the non-verbal messages (facial and body postures) that I send to others.

I have the necessary knowledge to know when to raise my personal issues with others and get advice

from.

When the victims are sad and upset, I can easily empathize with them.

In dealing with the injured, I use positive mood and behavior.

I usually behave logically and wisely.

I set a goal for myself and stick to it.

My will determines my success.

I do not lose hope in difficult situations.

I try to be patient with the aggressive behavior of the injured.

My ability on relief missions is greater than the assigned tasks.

The participation level of the 77-item measurement scale was obtained by analyzing the main components, with the lowest and highest participation levels of 0.565 and 0.785 belonging to items 37 (after trying to solve a problem in a certain way, I compare the real consequences with the consequences I expected) and item 94 (I am striving to achieve group goals), respectively. The participation level of other factors was between these two values.

By examining the commonalities and factor loads before rotation and the final selection of the factors after the rotation, the items were finally included in six factors of resilience, selfmanagement, psychological hardiness, decisionmaking, problem-solving ability, and EI.

\section{Analysis of factors identified}

First factor: The first factor explained $22.101 \%$ of the variance, which as Table 5, its minimum load of 0.404 was related to the factor of consulting and increased problem-solving ability and its maximum load of 0.728 was associated with the ability to adapt to conditions. This factor was more indicative of resilience in times of crisis. The reliability coefficient of this factor was 0.94 , indicating a high reliability coefficient.

Second factor: The second factor explained $3.919 \%$ of the variance; according to Table 6 , its lowest load is 0.380 associated with the items of Whenever I have a problem, there is no one to count on his/her help and I try to manage the critical conditions, and its highest load is 0.501, related to self-regulation. This factor relies more on the self-management of the relief workers. The reliability coefficient of this factor was 0.95 , indicating its appropriate reliability. The fourth item of this factor was numbered inversely.
Table 6. Empowerment scale rotation matrix (Second factor)

\begin{tabular}{lc} 
Item & $\begin{array}{c}\text { Factor } \\
\text { coefficient }\end{array}$ \\
$\begin{array}{l}\text { Whenever I have a problem, there is } \\
\text { no one to count on his/her help. }\end{array}$ & 0.380 \\
$\begin{array}{l}\text { When I struggle with the challenges } \\
\text { and difficulties of rescue operations, }\end{array}$ & 0.432 \\
$\begin{array}{l}\text { I see myself a capable person. } \\
\begin{array}{l}\text { I use positive mood and behavior in } \\
\text { dealing with the injured. }\end{array}\end{array}$ & 0.430 \\
$\begin{array}{l}\text { When helping the injured, I act } \\
\text { emotionally. }\end{array}$ & 0.355 \\
I try to manage critical situations. & 0.501 \\
\hline
\end{tabular}

Third factor: The third factor explained $2.753 \%$ of the variance, which according to Table 7 has a minimum load of 0.386 for high tolerance and a maximum load of 0.478 for effort despite obstacles, and this factor mainly focuses on the psychological hardiness of the relief workers. The reliability coefficient of this factor was 0.93 , which indicates its appropriate reliability. The first and third items of this factor were numbered in reverse.

Table 7. Empowerment scale rotation matrix (Third factor)

\begin{tabular}{l|c}
\hline Item & $\begin{array}{c}\text { Factor } \\
\text { coefficient }\end{array}$ \\
$\begin{array}{l}\text { Hearing the pain and worries of others } \\
\text { has an adverse effect on me. }\end{array}$ & -0.424 \\
$\begin{array}{l}\text { I am usually a tolerant person. } \\
\text { I do not believe in the proverb "The } \\
\text { darkest hour is that before dawn". }\end{array}$ & 0.386 \\
$\begin{array}{l}\text { Regardless of the obstacles ahead, I } \\
\text { strive to achieve my goals. }\end{array}$ & 0.478 \\
$\begin{array}{l}\text { In most cases, I stand up to the stressful } \\
\text { and exhausting circumstances of an }\end{array}$ & 0.412 \\
accident to achieve success. & \\
\hline
\end{tabular}


Fourth factor: The fourth factor explained $2.36 \%$ of the variance, which, based on Table 8 , relies on the problem-solving ability of the relief workers. The reliability coefficient of this factor was 0.92 , which is an appropriate reliability.

Table 8. Empowerment scale rotation matrix (Fourth factor)

\begin{tabular}{l|c}
\hline Item & $\begin{array}{c}\text { Factor } \\
\text { coefficient }\end{array}$ \\
\hline $\begin{array}{l}\text { I can think of a solution for any } \\
\text { problem I face. }\end{array}$ & 0.415 \\
\hline
\end{tabular}

Fifth factor: The fifth factor explained $2.136 \%$ of the variance, which, according to Table 9, relies on the decision-making ability of the relief workers. The reliability coefficient of this factor was 0.94 , indicating its appropriate reliability.

Table 9. Empowerment scale rotation matrix (Fifth factor)

\begin{tabular}{l|c}
\hline Item & $\begin{array}{c}\text { Factor } \\
\text { coefficient }\end{array}$ \\
\hline $\begin{array}{l}\text { I am usually satisfied with most of } \\
\text { the decisions I have made in my life. }\end{array}$ & -0.377 \\
\hline
\end{tabular}

Sixth factor: The sixth factor explained $1.689 \%$ of the variance, which relies on EI of the relief workers as Table 10. The reliability coefficient of this factor was 0.94 , which indicates its appropriate reliability. This factor was inversely numbered.

Table 10. Empowerment scale rotation matrix (Sixth factor)

\begin{tabular}{l|c} 
Item & $\begin{array}{c}\text { Factor } \\
\text { coefficient }\end{array}$ \\
\hline Others can easily make me angry. & 0.420 \\
\hline
\end{tabular}

It should be noted that the validity coefficient of the empowerment scale was also examined by the retest method as described in Table 11, with the amount obtained as 0.95 .

Table 11. Validity coefficients of factors

\begin{tabular}{l|c}
\hline Factor & $\begin{array}{c}\text { Alpha } \\
\text { coefficient }\end{array}$ \\
\hline Resilience & 0.94 \\
Self-management & 0.95 \\
Psychological hardiness & 0.93 \\
Problem-solving ability & 0.92 \\
Decision-making & 0.94 \\
EI & 0.94 \\
\hline
\end{tabular}

\section{Discussion and Conclusion}

On the basis of EFA, out of the first 10 factors, the six factors of resilience, self-management, psychological hardiness, problem-solving ability, decision-making, and EI had the greatest effects on psychological empowerment, with the most important factor being the factor of resilience which explained about $23 \%$ of the variance.

Hadinia in a study showed that there was a significantly positive relationship between psychological empowerment and resilience (14).

In this study, this factor covered most of the items and was recognized as the most important factor in empowering relief workers and rescuers of the Red Crescent Society, which as a key component requires special attention in future studies and population policies.

The second factor identified in this study was self-management or self-regulation, which explained nearly $3 \%$ of variance. Self-regulation is the ability of an individual to adjust his or her behaviors in accordance with the conditions and changes in the external and internal environment. It also shows a person's capacity to organize his or her behaviors according to his or her goals. In other words, self-regulation is a kind of selfmanagement of behaviors. An individual who benefits from a kind of self-management in regulating his emotions and feelings, monitors his actions through a subset of psychological functions such as self-observation, self-judgment, and self-reaction and acts properly in his value judgments and decisions (15).

In their study, Pahlavan Sadegh and Abdollahi achieved results indicating the direct effect of psychological empowerment with the theme of self-determination, risk-taking, personal growth, and higher responsibility in decision-making on self-efficacy as well as the direct impact of both structures on the level of self-regulation and formation of job satisfaction and subsequently, the success of the organization (16).

The third factor identified in this study was psychological hardiness; in a study conducted by Dayyeri et al., it was shown that there was a significant relationship between psychological hardiness, stress management strategies, and selfefficacy in relief workers (17).

Besides, the dimensions of hardiness (commitment and struggle) had a significant relationship with the components of coping methods. Ansari et al. suggested in their study that 
there was a significant relationship between empowerment of the employees and the job challenge factor (18).

Other factors such as the fourth factor of problem-solving ability, the fifth factor of decision-making, and the sixth factor of EI were also among the identified factors effective on the occupational psychological empowerment of the relief workers.

In a study, Navidzade showed that teaching problem-solving skills with the approach of empowering social work had a significant effect on increasing the level of individual-social adjustment of the study community (19).

Attarian concluded in his study that one of the factors affecting empowerment is the readiness and ability to make decisions (20). The studies by Jalali et al. (21), Arabi (22), Seyed Javadein et al. (23), Mohammadi (24), Zairi and Jarrar (25), and Majdodin (26) suggested that participation in decision-making is one of the factors influencing empowerment. Mehrabian et al. found in their study that EI and its dimensions could predict the ground for the employee empowerment (27).

In their study, Abedi et al. revealed that there was a high and significant relationship between the components of EI (happiness, enduring psychological pressure, self-expression, realism, impulsive control, flexibility, responsibility, and self-actualization) and empowerment of human resources (28).

Given the dimensions identified in this study, policymakers in the Red Crescent Society need to consider the factors of resilience, selfmanagement, psychological hardiness, problemsolving ability, decision-making, and EI in choosing relief workers. The tool developed can also help volunteer psychologists in the Red Crescent Society health centers to assess the occupational psychological empowerment of the relief workers. Furthermore, this tool can be employed as a suitable means for admitting volunteers to this volunteer activity and measuring the psychological empowerment of relief workers before training and two months after the training.

Programmers can also use this tool to assess needs, plan, and conduct training courses and workshops for training, empowerment, reinforcement, and promotion of psychological empowerment components among the relief workers. Psychological empowerment training will increase the job compatibility and vitality of the relief workers and rescuers, thus increasing the ability of this group to help the injured during disasters and accidents.

Based on the findings of the present study, resilience was recognized as the most important factor influencing the empowerment of the relief workers, so in order to support relief workers and reduce the pressures and stresses of accident relief and prevent them from becoming more severe psychological problems, it is necessary to provide special counseling and support services to relief workers in order to increase resilience among them, in addition to providing effective interventions and training.

Given the need to achieve a credible tool at the national level to measure the occupational psychological empowerment of relief workers, the researcher recommends repeating the study in other cultural contexts and target groups, including relief workers from other provinces, firefighters, and other health workers. The results of this study can be considered by researchers in achieving such an important goal and developing tools to measure the psychological empowerment of the relief workers.

\section{Acknowledgments}

The researcher would like appreciate all the relief workers and rescuers who cooperated in conducting this study.

MSc Thesis in Guidance and Counseling, Approved by the School of Educational Sciences and Psychology, South Tehran Branch, Islamic Azad University, Tehran, Iran

\section{Conflict of Interests}

Authors have no conflict of interests.

\section{References}

1. Kanwal A, Imam A. The theory and concept of psychological empowerment. Academic Journal of Social Sciences 2017; 1(3): 261-5.

2. Conger JA, Kanungo RN. The empowerment process: Integrating theory and practice. Acad Manage Rev 1988; 13(3): 471-82.

3. Spreitzer GM. Psychological empowerment in the workplace: Dimensions, measurement, and validation. Acad Manage J 1995; 38(5): 1442-65.

4. Thomas KW, Velthouse BA. Cognitive elements of empowerment: An "Interpretive" model of intrinsic task motivation. Acad Manage Rev 1990; 15(4): 666-81. 
5. Gist ME. Self-efficacy: Implications for organizational behavior and human resource management. Acad Manage Rev 1987; 12(3): 472-85.

6. Deci EL, Connell JP, Ryan RM. Self-determination in a work organization. J Appl Psychol 1989; 74(4): 580-90.

7. Ashforth BE. The experience of powerlessness in organizations. Organ Behav Hum Decis Process 1989; 43(2): 207-42.

8. Spreitzer GM. Social structural characteristics of psychological empowerment. Acad Manage J 1996; 39(2): 483-504.

9. Cameron KA, Whetten DA. Empowerment and delegation of authority. Trans. Orei Yazdani B. Tehran, Iran: Institute of Research and Management Education; 2003. [In Persian].

10. Abdollahi B, Naveh Ibrahim A. Employee empowerment: The Golden Key to Human Resource Management. Tehran, Iran: Virayesh Publications; 2006. [In Persian].

11. Douglas PD. Disasters and helpers: Psychological dynamics and implications for counseling. Couns Psychol Q 1989; 2(3): 303-22.

12.Zorieh Amn H. Rambo Syndrome in the Rescue Team and Effective Measures against it. Proceedings of the $3^{\text {rd }}$ International Congress on Health, Medication and Crisis Management in Disaster; 2006 Dec. 12; Tehran, Iran. [In Persian].

13. Lee $M$, Koh J. Is empowerment really a new concept? The International Journal of Human Resource Management 2001; 12(4): 684-95.

14. Hadinia $P$. Investigating the relationship between psychological empowerment and resilience among nurses of Namazi and Shahid Faghihi hospitals in Shiraz [MSc Thesis]; Shiraz: Payame Noor University; 2012. [In Persian].

15. Arian Poor E. Investigating the role of social orientation and self-control in moral behavior according to the mediating role of altruism and spiritual experience in students of Tabriz University [MSc Thesis]; Tabriz, Iran: University of Tabriz; 2011. [In Persian].

16. Pahlavan Sadegh A, Abdollahi B. Structural model of relationship between psychological empowerment and job satisfaction, and mediating role of self-efficacy and self-regulation. Journal of Management and Planning in Educational Systems 2015; 8(14): 85-112. [In Persian].

17. Dayyeri Z, Barzegar M, Sarvghad S. The relationships between coping strategies with stress, self-efficacy and psychological hardiness in relief workers of Red Crescent society of Kohgiluyeh and Boyer-Ahmad province. Sci J Rescue Relief 2015; 6(4): 66-76.

18. Ansari M, Oskuei V, Hosseini A. Identifying the factors and developing the human resource empowerment conceptual model in ICT ministry (Case Study). Journal of Public Administration 2011; 3(7): 23-40. [In Persian].
19. Navidzade F. Effectiveness of problem solving training by empowerment approach to social work on personal and social adjustment of Girls in Residential Care Center [MSc Thesis]; Tehran, Iran: University of Social Welfare and Rehabilitation; 2015. [In Persian].

20. Attarian F. Designing a system for empowering employees of government administrative bodies [PhD Thesis]; Tehran Iran: Science and Research Branch, Islamic Azad University; 2016. [In Persian].

21. Jalali R, Alvani SM, Hassanpour A, Mohebzadegan Y. Identification, and modeling effective factors in empowering managers. Journal of Teaching in Marine Sciences 2017; 4(1): 14-29.

22. Arabi MS. Examining the indicators of human resources empowerment strategy in Alborz Social Security Organization and presenting solutions to improve the situation [MSc Thesis]; Tehran, Iran: West Tehran Branch, Islamic Azad University; 2012. [In Persian].

23. Seyed Javadein SR, Heydari H, Shahbaz Moradi S. A study on employees' empowerment in service sector (case study of banking system). Journal of Public Administration 2009; 1(2): 75-88. [In Persian].

24. Mohammadi M. Evaluating ways to empower Birjand University staff [MSc Thesis]; Tehran, Iran: Tarbiat Modares University; 2001. [In Persian].

25. Zairi M, Jarrar YF. Employee empowerment-A UK survey of trends and best practices [Online]. [cited 2010]; Available from: URL: https://pdfs.semanticscholar.org/8565/a99eed02aca 3593111513aac8701c522f970.pdf

26. Majdodin A. Empowerment model for managers of higher education centers of the University of Applied Science and Technology [PhD Thesis]; Tehran, Iran: Allameh Tabataba'i University; 2012. [In Persian].

27. Mehrabian F, Ahmadinezhad M, Taheri M. The relationship between emotional intelligence and empowerment of staff in Guilan Health Centers. Iran J Med Educ 2016; 8(3): 44-51. [In Persian].

28. Abedi S, Zare S, Saeidipour B, Soltani A. The relationship between emotional intelligence with empowerment of human resources at Payame Noor University. Journal of Training \& Evaluation 2011; 4(15): 107-27. [In Persian]. 